\title{
Microstructures and Properties of Recycled Composites - Particle Reinforced Iron Matrix Functionally Graded Materials Fabricated by Centrifugal Casting
}

\author{
Yanpei Song ${ }^{1}$, Shuangxu $\mathrm{Bi}^{2}$, Xiuqing $\mathbf{L i}^{3}$ \\ Materials Science \& Engineering College, Henan University of Science and Technology, Luoyang, China \\ E-mail: asypei@mail.haust.edu.cn; $\{$ bbsx321, clixiuqing118\}@163.com \\ Received December 1, 2009; revised February 2, 2010; accepted February 8, 2010
}

\begin{abstract}
Microstructures and properties of recycled composites ring parts containing cast tungsten carbide particles $\left(\mathrm{CTC}_{\mathrm{p}}\right)$ in a bainitic matrix fabricated from dead or waste composites roll rings by centrifugal casting after remelting treatment, have been tested using SEM, EDS and XRD analyses as well as mechanical property testers. The test results show that the $\mathrm{CTC}_{\mathrm{p}}$ surface were partially dissolved into the liquid iron at $1650{ }^{\circ} \mathrm{C}$ during remelting. The undissolved $\mathrm{CTC}_{\mathrm{p}}$ in the $\mathrm{Fe}$ melt moved towards the outer region under the action of the centrifugal force during casting, which caused the formation of outer reinforced region and inner unreinforced region along the radial direction of the parts. SEM observation displays that the undissolved $\mathrm{CTC}_{\mathrm{p}}$ distribution in the outer region is even, and the volume fraction of them is increased with increasing rotational speed of the mold. Besides, mechanical tests of the parts show that the outer region exhibits superior hardness, and the inner region has sufficient impact toughness; the volume fraction of $\mathrm{CTC}_{\mathrm{P}}$ influences the mechanical properties. The dissolution-reprecipition of $\mathrm{CTC}_{\mathrm{P}}$ during centrifugal casting was also discussed.
\end{abstract}

Keywords: Recycled Composites; Centrifugal Casting; Mechanical Properties; Microstructures

\section{Introduction}

Work rolls for hot rolling mills have undergone numerous developments over the past few decades. With the development of high-speed hot rolling technology, work rolls are demanded not only to meet high resistance to wear and heat, but also to meet high strength-toug hness and stable operation [1]. While cemented carbide composite roll rings produced through powder metallurgy method possess excellent wear resistance and strength [2-4], an obvious disadvantage of them is the fact that such high-cost rolls are unable to be used as over-size or intermediate work rolls and are prone to fracture in service because of the low toughness, which causes substantial waste of raw materials and energy. As a consequence, the synthetic mechanical properties as well as technology cost of work rolls for hot rolling mills has always been of great concern to the roll designer or operator.

Metal matrix composites (MMCs), especially particlereinforced metal matrix composites (PRMMCs), have been paid increased attention and have been used extensively in industry over several years, due to its excellent mechanical and thermal properties. In recent years, by means of centrifugal casting technique we have developed a new type of composite roll (ring) made of iron-based functionally graded materials (FGM) reinforced with CTCP, i.e. FGM-PRMMC, which has surface reinforced region with high hardness and excellent wear resistance, and has inner un-reinforced region with high strength and toughness. Previous investigations of the newly-developed roll (ring) show that the working surface hardness and wear resistance are as almost high as those of the cemented carbide composite roll, and the impact toughness is nearly 4 to 8 times higher than that of the cemented carbide roll $[5,6]$. It is evident that application of the FGM-PRMMC roll (ring) will make it possible that the production cost of the work roll for high-speed wire mill can be reduced by half at least, compared to that of the cemented carbide roll (ring). Despite of these advantages, this technique still has several limitations such as the accumulated scrap or failure rolls in the industrial dump sites, which, if discarded or 
not reused, will cause substantial waste of energy sources and roll materials. From the point of view of economic significance, it's necessary to evaluate the technological economics of the common preparation process of composite roll, and thus the recycling or reuse of the scrap rolls attracts more manufacturers' attention. Accordingly, the current work specifically looks at the microstructures and mechanical performance of the recycled composites ring, i.e. the recycled FGM- PRMMC rings, which were fabricated by centrifugal casting technique. The aim of the present work is to estimate the possibility of reusing the accumulated scrap or failure roll rings made of FGMPRMMC mentioned above.

\section{Experimental Procedures}

\subsection{Fabrication of the Recycled Composites}

The dead or waste composites roll rings for remelting had been Fe-alloy matrix selectively reinforced with $\mathrm{CTC}_{\mathrm{p}}$ towards the outer surface region, and the volume fraction of them is about $75 \%$. The chemical compositions of the Fe-alloy matrix are given in Table 1.

A $50 \mathrm{~kg}$ medium frequency induction furnace was utilized to re-melt the waste roll rings after primary crushing. When the re-melting temperature was raised to about $1650^{\circ} \mathrm{C}$, the molten material containing liquid $\mathrm{Fe}$ alloy and solid $\mathrm{CTC}_{\mathrm{p}}$ was obtained, resulting in the uniform dispersion of particles in the molten matrix. Then the molten mixture was directly cast into a rotating horizontal centrifuge, as seen in Figure 1, and the centrifugal casting process was carried out with an rotational velocity of $780-920 \mathrm{rpm}$ while the pouring temperature of the material was set at $1500^{\circ} \mathrm{C}$. The ring castings obtained were $234 \mathrm{~mm}$ in the outer diameter, roughly 55 $\mathrm{mm}$ in wall thickness, and $78 \mathrm{~mm}$ in length. One of the recycled composites $t$ ring fabricated under the experimental conditions is shown in Figure 2. Figure 2(b) presents a difference in appearance between the outer surface region and the inner region of the centrifugally cast ring. The thickness of the outer reinforced region along the radial direction reaches 10 to $15 \mathrm{~mm}$ for the annular castings obtained in this study.

Table 1. Chemical composition of the matrix material of the roll rings for the remelting (wt, $\%$ ).

\begin{tabular}{cccccccccc}
\hline $\mathrm{C}$ & $\mathrm{Si}$ & $\mathrm{Mg}$ & $\mathrm{Ni}$ & $\mathrm{Mo}$ & $\mathrm{Re}$ & $\mathrm{S}, \mathrm{P}$ & $\mathrm{Fe}$ \\
\hline 3.4 & 2.2 & 0.05 & 3.2 & 0.3 & 0.07 & $<0.03$ & Balance \\
\hline
\end{tabular}

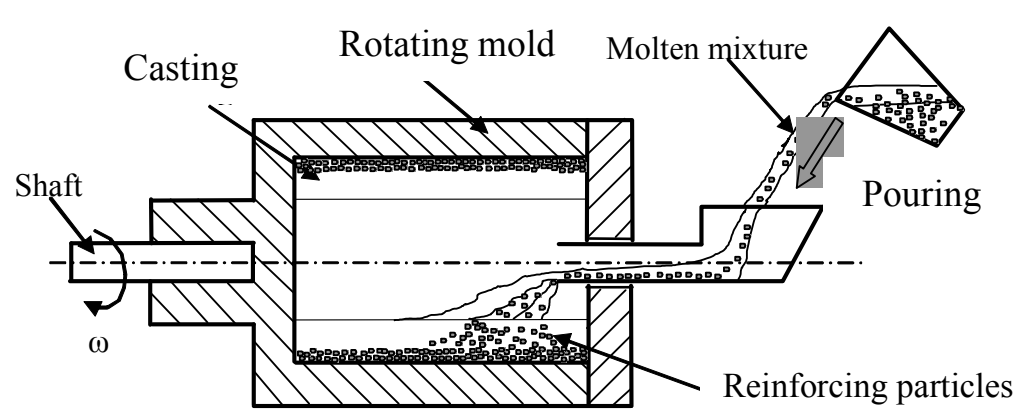

Figure 1. Schematic illustration of the centrifugal casting system used in this research.

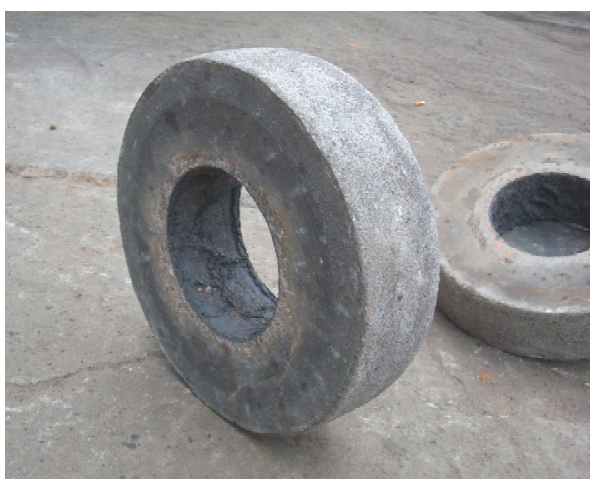

(a)

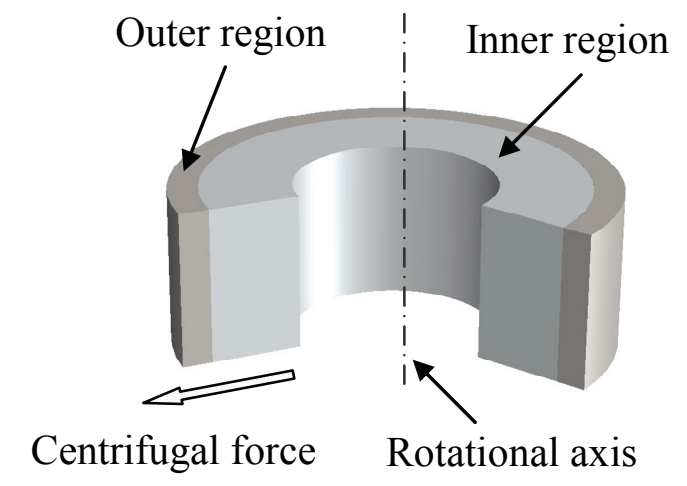

(b)

Figure 2. Presentation of the centrifugally cast ring: (a) photograph of the cast, and (b) schematic of the cast. 


\subsection{Mechanical Properties Tests}

Mechanical behavior tests for the recycled composites castings contain impact toughness and Rockwell hardness testing, respectively. The relevant test specimens were electron discharge machined from the rough castings. Impact toughness tests were conducted on an impact tester (Model JB294/147A). The impact specimens for the tests were blocks of $10 \times 10 \times 55 \mathrm{~mm}$. Impact toughness tests results were determined from three specimens. Rockwell hardness used was HR150D which was tested by using the HR150D hardness tester. The applied load was $150 \mathrm{~N}$. For each specimen, an average value of hardness was taken from at least five measurements.

\subsection{Microstructure Characterization}

All metallographic specimens were prepared for microstructure observation by standard metallographic polishing techniques and were etched with a solution of $4 \%$ nital to reveal the matrix microstructure. The microstructure and compositions were analyzed by using a scanning electron microscopy (SEM) with energy dispersive spectroscopy (EDS). The XRD analysis was performed on a Philips $\mathrm{X}$-ray diffractometer using $\mathrm{Cu}$ radiation at a voltage of $40 \mathrm{kV}$ and a current of $25 \mathrm{~mA}$ with a step size of $0.1^{\circ}$.

\section{Results and discussion}

\subsection{Hardness and Impact Toughness}

The mechanical properties of the recycled composites ring are shown in Figure 3. Along the radial direction of the annular sample, the mechanical properties are different. The outer surface region possesses a high hardness, which is beneficial to increasing its surface wear resistance; the inner region possesses an excellent impact toughness, improving the impact resistance of the ring. Therefore, such recycled composites ring can be used in heavy load and high speed conditions such as roller rings used in high-speed wire rolling mill. Besides, It can be observed that with an increase in rotational speed (from 780 to $920 \mathrm{rpm}$ ), the hardness values of the castings increase, while the impact toughness values somehow decrease.

\subsection{The undissolved CTCP Distribution in the Surface Reinforced Region}

The micrographs shown in Figure 4 present the CTCP distributions in the outer surface region of the castings fabricated at 780 and $920 \mathrm{rpm}$ rotational speed of the mold, respectively. The distribution of CTC-particles in

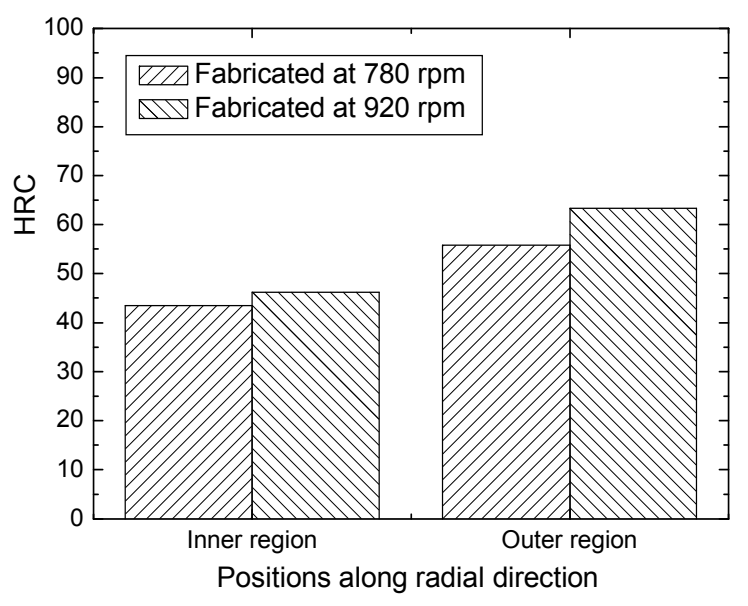

(a)

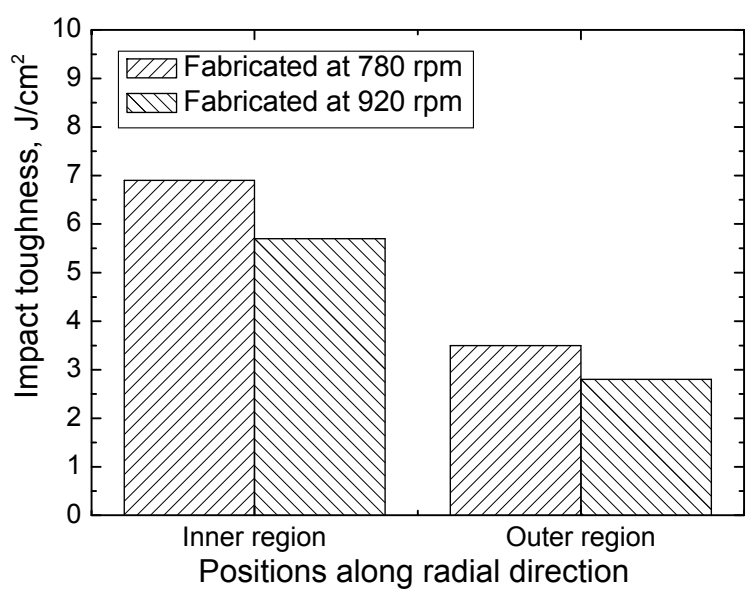

(b)

Figure 3. Mechanical properties comparison of the centrifugally cast rings: (a) hardness and (b) impact toughness.

the outer region of the casting, as shown in Figure 4, is even, and the volume fraction of them reaches about 54 vol. $\%$ at $780 \mathrm{rpm}$ (Figure 4(a)) and 70 vol. \% at 920 rpm (Figure 4(b)). That is to say, an intense segregation of the CTCP occurs towards the outer region of the casting when a higher centrifugal rotational speed is obtained.

Meanwhile, the average size and volume fraction of the CTCP in the recycled composites become smaller compared to those of the CTCP in the waste composites roll ring before remelting treatment (Figure 5). This may be duo to the fact that the CTCP were partially dissolved into the liquid iron during remelting treatment, and the extent of the partial dissolution varies in different remelting treatment, as shown in Figure 4. In one word, the segregation of the undissolved CTCP had occurred during the centrifugal casting which contributes to improving the hardness in the outer region as well as impact toughness in the inner region for the recycled composites ring. 


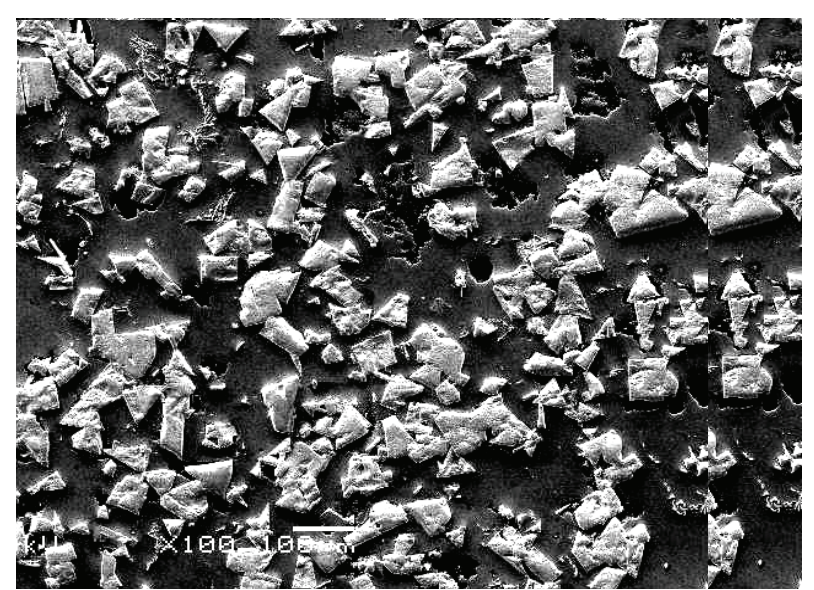

(a)

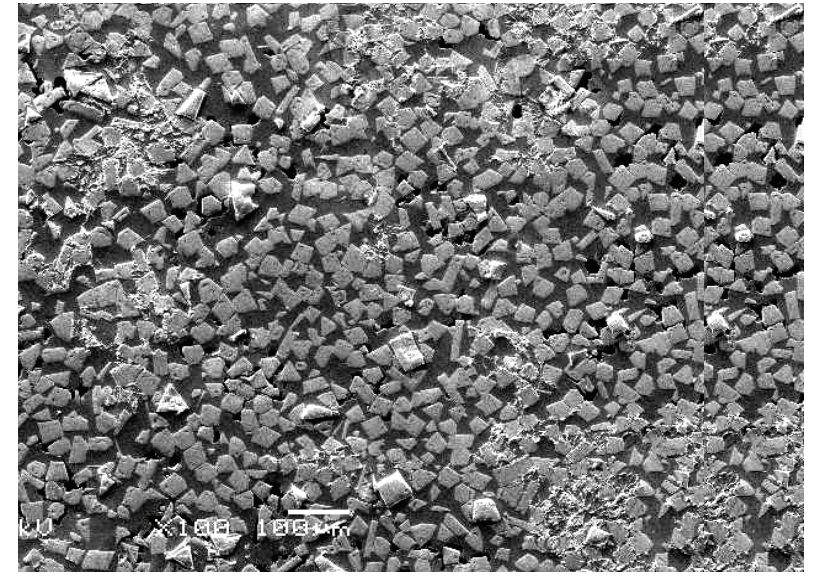

(b)

Figure 4. $\mathrm{CTC}_{\mathrm{p}}$ distributions in the outer region of the recycled composites rings fabricated at (a) $780 \mathrm{rpm}$, and (b) $920 \mathrm{rpm}$.

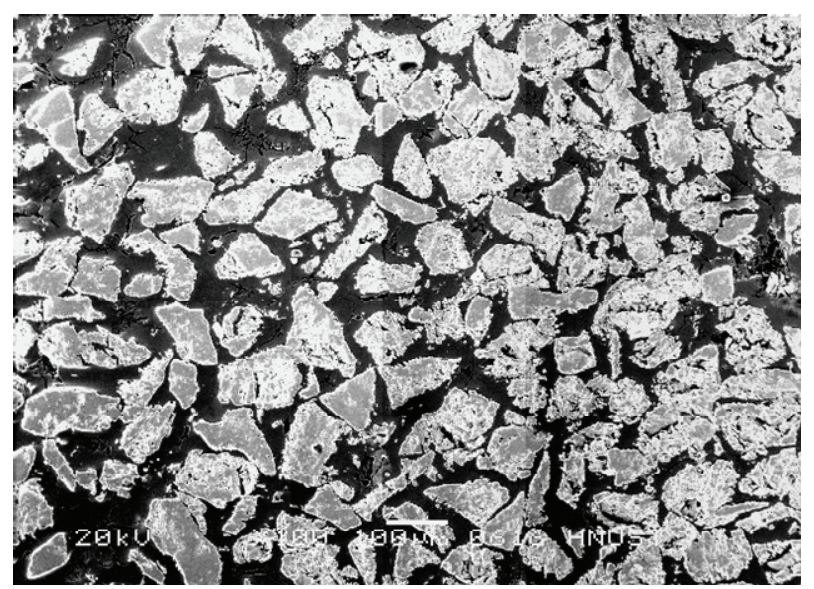

(a)

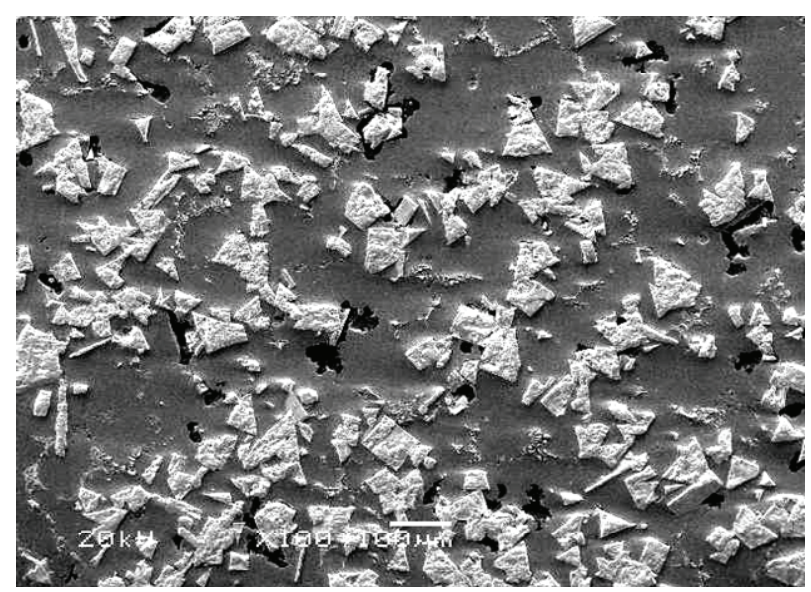

(b)

Figure 5. Comparison of CTC-particle distributions in the outer region of (a) the waste roll ring and (b) the recycled composites ring.

The particle segregation mentioned above occurred during the centrifugal casting because of the difference in density between the molten $\mathrm{Fe}-\mathrm{C}$ alloy and the $\mathrm{CTC}_{\mathrm{P}}$. The motion of the un-dissolved $\mathrm{CTC}_{\mathrm{P}}$ in viscous $\mathrm{Fe}-\mathrm{C}$ alloy melt under the action of centrifugal force can be determined by Stokes' law. Thus, the radial convection velocity of the undissolved $\mathrm{CTC}_{\mathrm{P}}$ towards the outer region during the centrifugal casting, $\boldsymbol{v}_{\text {cent, }}$ can be estimated as:

$$
v_{\text {cent }}=d_{2}\left(\rho_{\mathrm{p}}-\rho_{\mathrm{m}}\right) w^{2} r /(18 \eta)
$$

where $\boldsymbol{d}$ is diameter of un-dissolved CTC $\mathrm{C}_{\mathrm{P}} ;\left(\boldsymbol{\rho}_{\mathrm{p}}-\boldsymbol{\rho}_{\mathrm{m}}\right)$ is the density difference between the undissolved $\mathrm{CTC}_{\mathrm{P}}$ and the liquid Fe-C alloy; $\omega$ is the angle velocity based on 780 to 920rpm rotational velocity (calculated value: 41 to 48 $\mathrm{rad} / \mathrm{s}$ ) constant for a definite rotation but changeable; $\boldsymbol{r}$ is radius of the rotating arm of the particle; $\boldsymbol{\eta}$ is the coefficient of dynamic viscosity of $\mathrm{Fe}-\mathrm{C}$ alloy melt. As a result, the radial convection velocity of the undissolved
$\mathrm{CTC}_{\mathrm{P}}$ present in the melt, $\boldsymbol{v}_{\text {cent }}$, increases squarely as a function of the rotation angle velocity $\omega$. According to this analysis, we can conclude that increasing the value of $\omega$ will raise the value of $\boldsymbol{v}_{\text {cent, }}$, which will lead to an intense segregation of the particles towards the outer region of the casting. That's why the volume fraction of the un-dissolved particles in the particle-segregated region of the casting increases from 54 to 70 vol. \% when rotation angle velocity $\omega$ increase from 41 to 48 $\mathrm{rad} / \mathrm{s}$ (based on 780 to $920 \mathrm{rpm}$ rotational speed). Therefore, it is clear that if a higher volume fraction of undissolved $\mathrm{CTC}_{\mathrm{P}}$ in the outer region of the casting is expected, the rotational speed of the mold must be increased.

\subsection{Analysis on the Partial Dissolution and In-Situ Crystallization of CTC $_{P}$}

The SEM micrograph and EDS analysis of the recycled 
composite ring, towards the outer region, are shown in Figure 6. It is observed that small amounts of short rod-like crystallites were dispersed in the iron matrix, in addition to the undissolved $\mathrm{CTC}_{\mathrm{P}}$ in the iron matrix. EDS analysis shows that the short rod-like crystallites are composites carbides containing Fe, W, and $\mathrm{Ni}$.

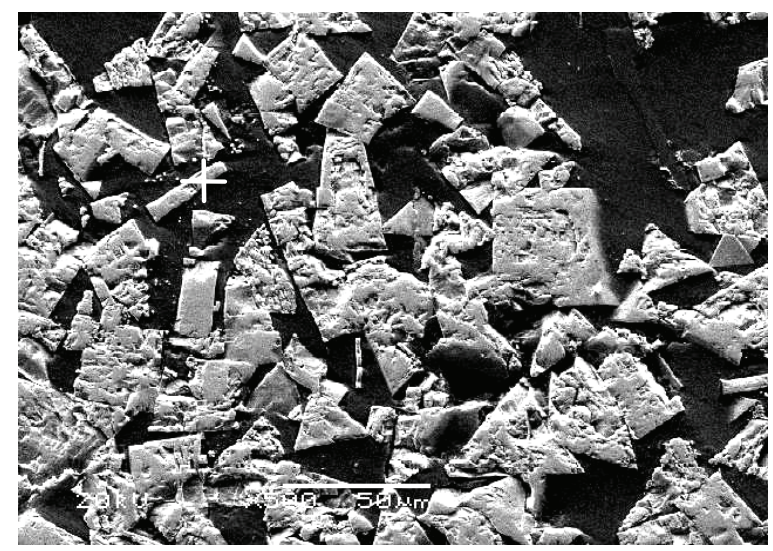

(a)
Figure 7 shows the microstructures of the recycled composite ring, towards the inner region. A lot of short rod-like and bone-like crystallites and nodular graphite phases can be observed from the iron matrix. The EDS result of the crystallites shows that they contain Fe, W, $\mathrm{Ni}$ and $\mathrm{C}$.

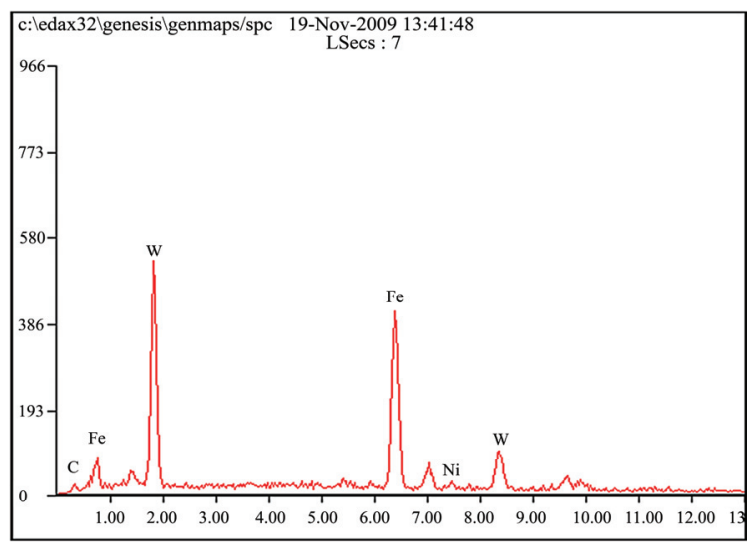

(b)

Figure 6. Microstructure of outer region of the recycled composites ring: (a) SEM micrograph, and (b) EDS analysis.

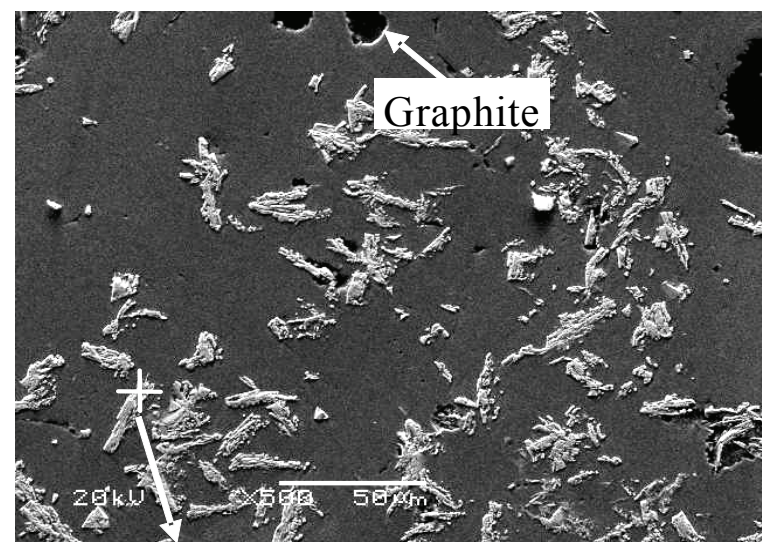

(a)

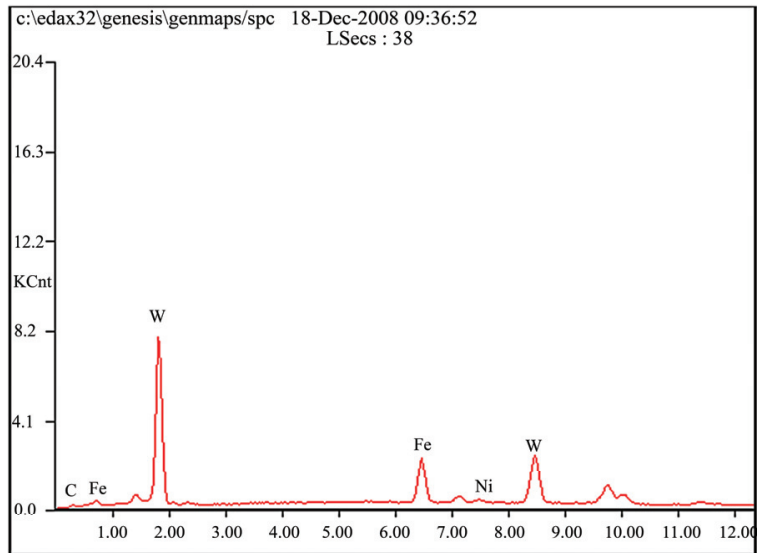

(c)

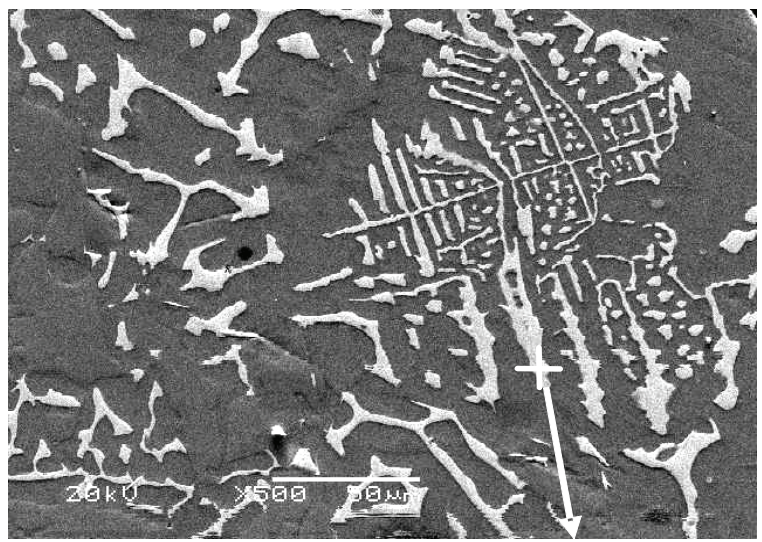

(b)

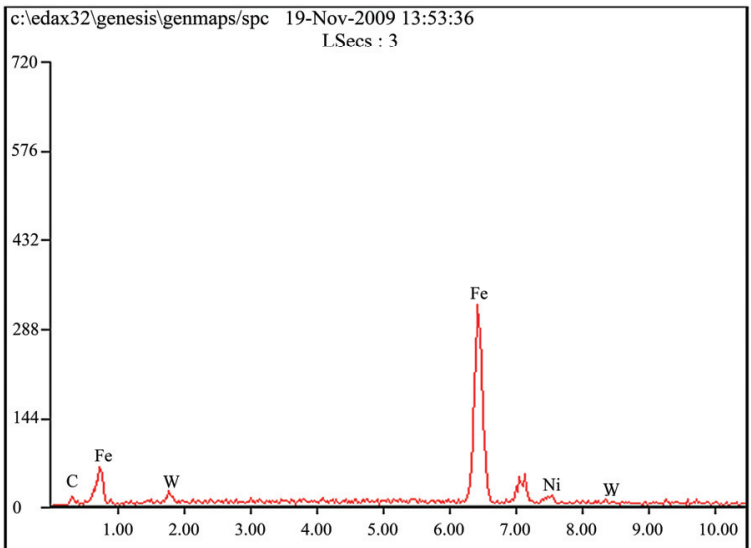

(d)

Figure 7. Microstructure of inner region of the recycled composites ring: (a-b) SEM micrographs, and (c-d) EDS analysis. 
It was discovered that there were a lot of coarser insitu crystallites with snowflake-like or branched shapes dispersed in the intermediate region between the outer and inner region (in Figure 8(a)). The EDS result of them shows that they are the composites carbides containing Fe, W, and Ni (in Figure 8(b)).

All above all, some in situ crystallites with various sizes and shapes were precipitated in the iron matrix from the outer region to the inner region. Concerned reference [7] shows that tungsten carbide (WC) is an interphase of transition-metal carbide, with simple hexagonal lattice, considerably high microhardness value of up to HM $1870 \mathrm{~kg} / \mathrm{mm}^{2}(18.326 \mathrm{GPa})$, melting temperature of $2700^{\circ} \mathrm{C}$ and density of $15.7 \mathrm{~g} / \mathrm{cm}^{3}$, and can almost be wetted completely by $\mathrm{Fe}-\mathrm{C}$ melt i.e. the wetting angle of $\mathrm{Fe}-\mathrm{C}$ melt on tungsten carbide particle, $\mathrm{u} \approx 0^{\circ}$. Besides, the solubility of WC in the Fe-melt approaches about $7 \%$

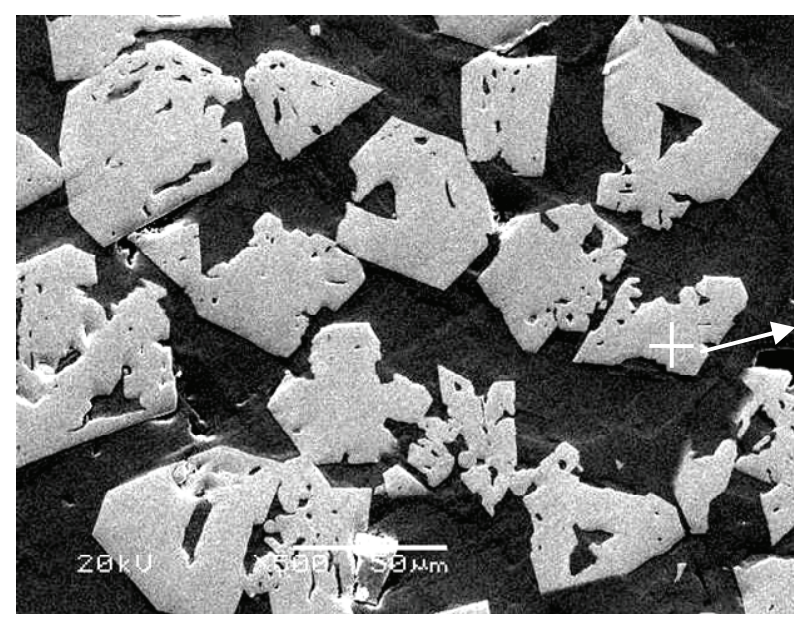

(a)

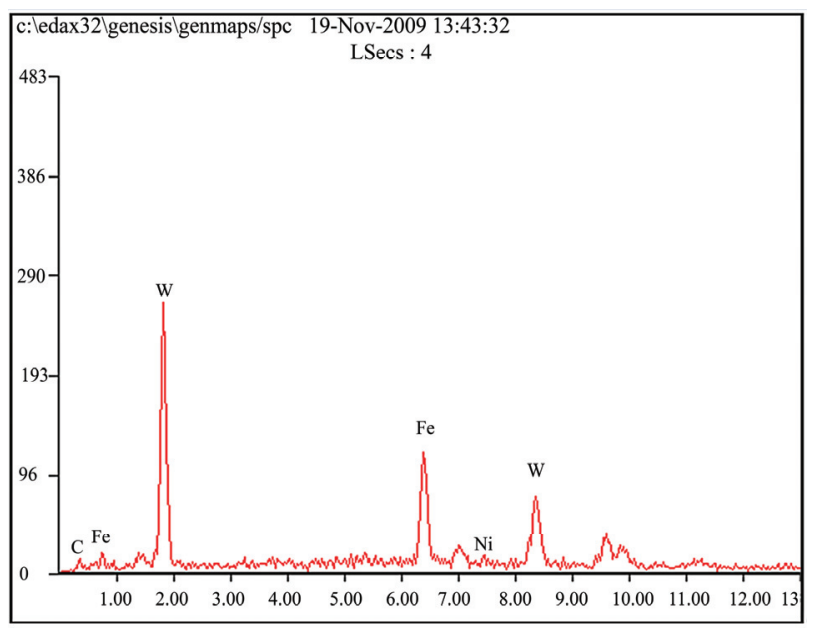

(b)

Figure 8. Microstructure of intermediate transitional region of the recycled composites ring: (a) SEM micrograph, and (b) EDS analysis.

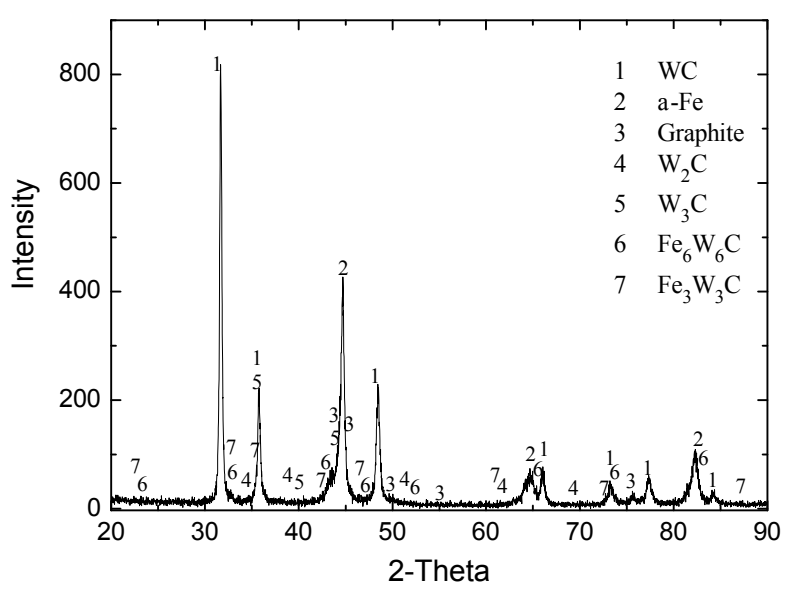

Figure 9. XRD patterns of $\mathrm{Fe}-\mathrm{C}$ alloy matrix in the inner region.

at $1250^{\circ} \mathrm{C}$, which indicates that WC-powder is dissolved and then separated from the matrix during the sintering of high-speed steel powders and WC powders. Especially, the melting temperature $\left(2525^{\circ} \mathrm{C}\right)$ of $\mathrm{CTC}_{\mathrm{P}}$, i.e. eutectic composed of $\mathrm{WC}$ and $\mathrm{W}_{2} \mathrm{C}$, is lower than that of WC particle so that the dissolution of the $\mathrm{CTC}_{\mathrm{P}}$ in $\mathrm{Fe}-$ melt is relatively easy. Thus, the dissolution of the $\mathrm{CTC}_{\mathrm{P}}$ in Fe-melt occured during the remelting process, which caused the supersaturated Fe-C-W alloy melt during the cooling process, but this dissolution is incomplete, namely the surface of $\mathrm{CTC}_{\mathrm{P}}$ had been partially dissolved. Finally, the in-situ crystallites were separated from the iron alloy during the casting process. Further XRD analysis shows that these in-situ crystallites contain WC, $\mathrm{W}_{2} \mathrm{C}, \mathrm{W}_{3} \mathrm{C}, \mathrm{Fe}_{6} \mathrm{~W}_{6} \mathrm{C}$ and $\mathrm{Fe}_{3} \mathrm{~W}_{3} \mathrm{C}$ (Figure 9), which are extremely wear-resistant.

\subsection{High Alloying Fe-C Alloy Matrix}

As can be seen from Figure 10, the iron matrix of the recycled composite ring shows bainitic microstructure. The EDS-analysis result of the iron matrix shows that they contains tungsten (W) elements, which suggests that the $\mathrm{Fe}-\mathrm{C}$ alloy matrix had been high alloyed by the previously dissolved $\mathrm{CTC}_{\mathrm{P}}$ because of the imcomplete separation of the dissolved $\mathrm{CTC}_{\mathrm{P}}$.

Reference [7] indicates that tungsten (W) is an important alloying element for high-speed steel bonded carbide products due to the fact that it can stabilize $\alpha$-phase zone and minify $\gamma$-phase zone in the Fe-C alloy phase diagram. As for high-speed steel, it possesses a good red hardness since the tungsten element present in the steel not only forms wear-resistant complex interphases and raises the decomposition temperature of tempered martensite after quench operation, but also retards the decomposition, precipitation and agglomeration of the martensite. Besides, tungsten element present in the high speed steel 

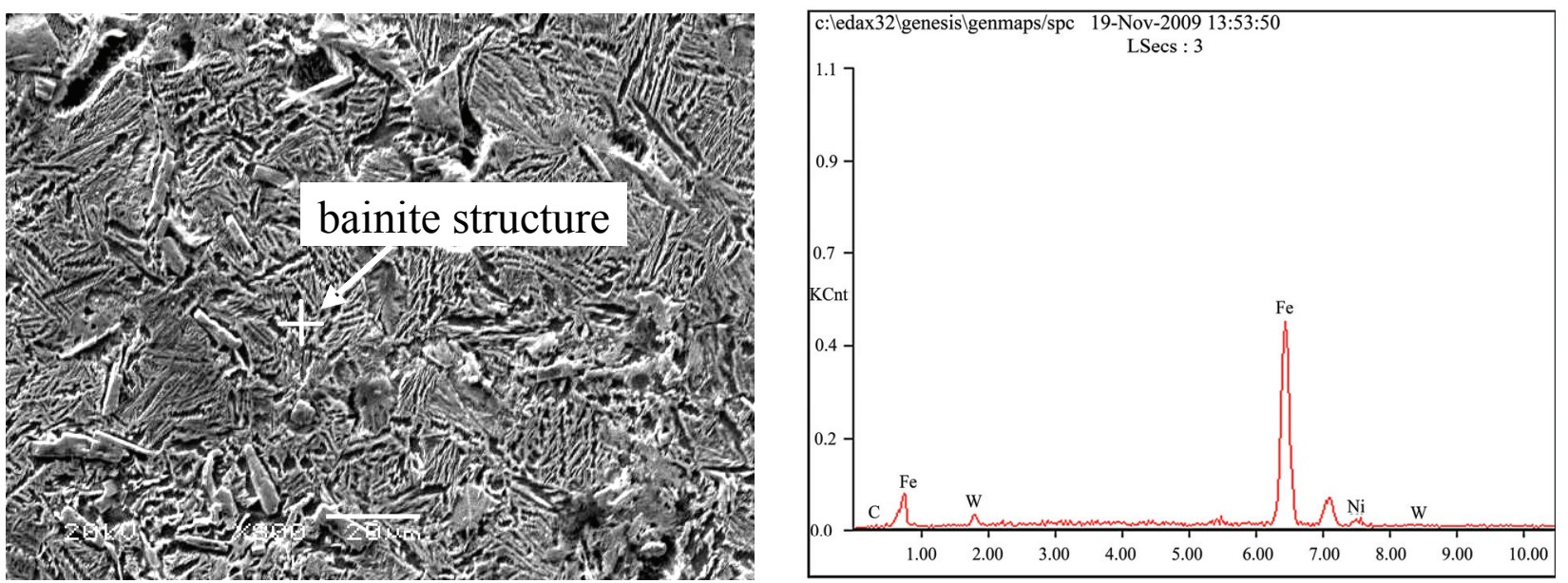

Figure 10. Microstructure analysis of Fe-C alloy matrix in the inner region: (a) scanning electron microscope (SEM) image, and (b) X-ray energy spectrum (EDS).

can cause the tempering secondary hardening of the steel under the $560^{\circ} \mathrm{C}$ tempering condition. Therefore, the matrix alloying of the recycled composite ring can contribute to the right selection of the heat treatment for the parts, so as to improve the overall physical and mechanical properties of the products so as to meet the requirements of the parts worked at high temperature.

\section{Conclusions}

In the present work, we have examined the microstructures and properties of the recycled composites rings fabricated by centrifugal casting process. The results of the study are stated as follows.

1) The undissolved $\mathrm{CTC}_{\mathrm{p}}$ (with higher bulk density than liquid Fe-alloy) segregate towards the outer surface region with a thickness of 10-15 $\mathrm{mm}$. The undissolved $\mathrm{CTC}_{\mathrm{P}}$ distribution in the outer region is even.

2) The outer surface region of the castings possesses a high hardness, and the inner region possesses an excellent impact toughness. So the rings obtained can be used in heavy load and high speed conditions such as roller rings for high-speed wire rolling mill.

3) With the centrifugal rotational speed increasing from 780 to $920 \mathrm{rpm}$, the volume fraction of the undissolved $\mathrm{CTC}_{\mathrm{P}}$ in the outer region increased from 54 to 70 vol. \%, which had led to an increase in the hardness and a decrease in the impact toughness.

4) The partial dissolution of the $\mathrm{CTC}_{P}$ surface in molten $\mathrm{Fe}-\mathrm{C}$ alloy had occurred during the remelting process and then some in situ crystallites with various sizes and shapes were precipitated in the iron matrixfrom the outer region to the inner region. These crystallites are composites carbides containing $\mathrm{Fe}, \mathrm{W}$, and $\mathrm{Ni}$.
5) EDS-analysis shows that the Fe-C alloy matrix had been high alloyed by the partially dissolved $\mathrm{CTC}_{\mathrm{P}}$, which could contribute to improving the overall physical and mechanical properties of the new products so as to meet the requirements of the parts worked at high temperature.

\section{References}

[1] M. Pellizzari, D. Cescato and M. G. De Flora, "Hot Friction and Wear Behaviour of High Speed Steel and High Chromium Iron for Rolls," Wear, Vol. 267, 2009, pp. 467-475.

[2] R. K. Viswanadham and P. G. Lindquist, "TransformationToughening in Cemented Carbides: Part I. Binder Composition Control," Metallurgical and Materials Transactions A, Vol. 18A, 1987, pp. 2163-2173.

[3] B. Uhrenius, "Phase Diagrams as a Tool for Production and Development of Cemented Carbides and Steels," Powder Metallurgy, Vol. 35, No. 3, 1992, pp. 203-210.

[4] R. Cooper, S. A. Manktelow, F. Wong and L. E. Collins, "The Sintering Characteristics and Properties of Hard Metal with Ni-Cr Binders," Materials Science and Engineering A, Vol. A105-A106, 1988, pp. 269-273.

[5] Y. P. Song, H. Yu, J. G. He, "Elevated Temperature Sliding Wear Behavior of $\mathrm{WC}_{\mathrm{P}}$-Reinforced Ferrous Matrix Composites," Journal of Matierals Science, Vol. 43, 2008, pp.7115-7120.

[6] Y. P. Song, H. Yu and X. M. Mao, "Wear Behavior of $\mathrm{WC}_{\mathrm{P}} / \mathrm{Fe}-\mathrm{C}$ Composites under High-Speed Dry Sliding," Journal of Materials Science, Vol. 43, No.8, 2008, pp. 2686-2692.

[7] "High-Speed Steel Sintered Hardmetals," Zhuzhou Hardmetal Works, Metallurgical Industry Press, 1982, pp. 86-92. 